\title{
How Do Police Respond to Stalking? An Examination of the Risk Management Strategies and Tactics Used in a Specialized Anti-Stalking Law Enforcement Unit
}

\author{
Jennifer E. Storey • Stephen D. Hart
}

Published online: 13 January 2011

(C) The Author(s) 2011. This article is published with open access at Springerlink.com

\begin{abstract}
How do police respond to and manage complaints of stalking? To answer this question, we conducted a 3-phase study. First, we reviewed the literature to identify risk management tactics used to combat stalking. Second, we asked a group of police officers to review those tactics for completeness and group them into categories reflecting more general risk management strategies. The result was 22 categories of strategies. Finally, we used qualitative methods to evaluate the files of 32 cases referred to the specialized anti-stalking unit of a metropolitan police department. We coded specific risk management tactics and strategies used by police. Results indicated that a median number of 19 specific tactics from 7 general strategies were used to manage risk. Also, the implementation of strategies and tactics reflected specific characteristics of the cases (e.g., perpetrator risk factors, victim vulnerability factors), suggesting that the risk management decisions made
\end{abstract}

This paper is based on a thesis submitted by J. E. Storey in partial fulfillment of the requirements for a Master's degree in psychology at the Department of Psychology, Simon Fraser University. J. E. Storey was supported by a graduate studentship awarded by the Social Sciences and Humanities Research Council of Canada. The authors gratefully acknowledge the cooperation and assistance of the Vancouver Police Department, and in particular the anti-stalking detectives of the Domestic Violence and Criminal Harassment Unit. The views expressed herein are those of the authors and do not necessarily reflect those of the Social Sciences and Humanities Research Council of Canada or the Vancouver Police Department.

J. E. Storey $\cdot$ S. D. Hart $(\bowtie)$

Department of Psychology, Simon Fraser University, 8888 University Drive,

Burnaby, British Columbia, Canada, V5A 1S6

e-mail: hart@sfu.ca

S. D. Hart

Faculty of Psychology, University of Bergen,

Bergen, Norway by police were indeed strategic in nature. Qualitative analyses indicated that some of the strategies and tactics were more effective than others. We discuss how these findings can be used to understand and use stalking risk management more generally, as well as improve research on the efficacy of risk assessment and management for stalking.

Keywords Stalking $\cdot$ Management $\cdot$ Policing

\section{Introduction}

Stalking or criminal harassment (as it is called in the Canadian Criminal Code) may be defined as "unwanted and repeated communication, contact, or other conduct that deliberately or recklessly causes people to experience reasonable fear or concern for their safety or the safety of others known to them" (Kropp et al. 2008a, p. 1). The lifetime prevalence of stalking victimization in Canada is approximately $4 \%$ for women and $2 \%$ for men (Canadian Centre for Justice Statistics 2005), which is lower than but comparable to the estimated lifetime prevalence of $7 \%$ for women and 2\% for men in the United States (Basile et al. 2006) and 1.4\% over a 12 month period (Baum et al. 2009).

There is little doubt that stalking is a common crime and one that often causes serious physical and psychological harm to victims (Mullen et al. 2006; Pathé and Mullen 1997). Stalking is also a difficult crime to manage due to the heterogeneous nature of and motives for stalking, as well as the diverse personal characteristics of stalkers and their victims (Kropp et al. 2002; Meloy 1997; Mullen et al. 2000a). Given these characteristics, what can or should police do to stop stalkers and protect victims? Perhaps due to the complex nature of stalking or its relatively recent criminalization, no well-developed taxonomy of risk man- 
agement approaches is used by police in stalking cases. The existing research literature offers some guidance in this area, but is neither uniform nor complete.

\section{Existing Literature on Risk Management}

The existing literature on approaches to managing risk for stalking can be divided into four distinct areas: practice recommendations for risk management of stalkers; surveys of risk management approaches used by victims; surveys of risk management approaches used by police; and evaluations of the efficacy of specific approaches, such as issuing court orders prohibiting the stalker from contacting the victim (e.g., criminal or civil peace bonds, restraining orders, and protective orders; see discussions by Baum et al. 2009; Brewster 1998; Hart 1996; Fisher et al. 2000; Meloy 1997; Nicastro et al. 2000; Spitzberg 2002; Tjaden and Thoennes 1998), providing alarms to victims that notify police directly when activated (e.g., personal alarm pendants and residential alarms; see discussions by Römkens 2006; Victim Services Toronto 2008), and an intensive case management intervention for victims (Spence-Diehl 2004). As the focus of this paper is to investigate and understand the diversity of risk management approaches, we now turn to a review of the literature in the first three of these areas.

\section{Practice Recommendations}

Several authors have discussed general recommendations regarding the practical management of risk for stalking in various contexts (e.g., Alison and Alison 2005; McCann 2001; Meloy 1997; Meloy 1998; Meloy et al. 2008; Mullen et al. 2006; Pathé et al. 2001; Turner and Gelles 2003; White and Cawood 1998). Although sensible and grounded in practice, these recommendations have several limitations for use by police. First, their content is selective, reflecting the personal views and experiences of the authors rather than empirical research. This means the recommendations may have important gaps or omissions. Second, some recommendations focus on management approaches that can be implemented by victims or others, such as human resources and security professionals, rather than police. Third, given the importance of mental health variables in terms of the motivation, treatment, and management of stalking, many of the practice recommendations focus primarily on clinical management by mental health professionals.

Practice recommendations for police are difficult to specify because police powers vary, depending on the laws of the jurisdiction in which they operate. For instance, police may have authority to suggest that the court impose a wide range of conditions for stalkers with respect to monitoring, supervision, and assessment or treatment.
Police in Canada are also able to give perpetrators formal warnings to cease their behaviour and have perpetrators sign such warnings to confirm their understanding of its contents. Police may also have the opportunity to offer or broker voluntary services for stalkers and victims such as counseling and faith-based services. But police powers are limited in some important respects; for example, police can recommend, but cannot force, victims or others to implement certain management tactics (e.g., victim moving residence, employer firing stalker).

\section{Victim Surveys}

Victim survey research involves asking victims directly about the kinds of actions they or others took to discourage stalkers and, less often, about the effectiveness of those actions. In some studies, stalking victims were identified in the course of surveys of the general population (i.e., a random sample of community residents) and responded to questions posed in person or over the telephone; in others, victims were self-identified and responded to questions posed over the internet. Regardless of the sampling method used, these surveys found victims used many different approaches to discourage stalkers. For example, in his meta-analysis, Spitzberg (2002) found 440 specific management tactics. One of the most commonly reported tactics was victim making a report or complaint to police. The rate of reporting varied greatly across other surveys, ranging from $17 \%$ to $41 \%$ at the low end (Baum et al. 2009; Bjerregaard 2000; Fisher et al. 2000) and $72 \%$ to $96 \%$ at the high end (Blaauw et al. 2002; Brewster 2001, 2003; Nicastro et al. 2000). Other commonly reported tactics included victim changing phone numbers (e.g., Bjerregaard 2000) or victim physically confronting the stalker (e.g., Nicastro et al. 2000). Tjaden and Thoennes (1998) found that the tactics most frequently endorsed by victims as effective included such things as victims moving and keeping their new residential information confidential. Baum et al. (2009) found that victims reported police warning the stalker to be most effective tactic, followed by the victim talking to the stalker and intervention by a family member.

Spitzberg (2002) grouped the various management tactics he identified into five general categories, representing fundamental interpersonal orientations (i.e., moving away, moving toward or with, moving against, moving inward, and moving outward). He then identified how often victims used at least one tactic from the various categories to manage violence risk. He found that most victims used relatively few types of tactics: The frequency with which tactics within each of the five categories were used ranged from about $7 \%$ to about $32 \%$.

Research using victim surveys is, unfortunately, of limited relevance to police who must respond to complaints 
of stalking. First, not all cases of stalking are referred to police, and those cases in which complaints are made to police typically differ in nature and severity. Specifically, studies have shown that complaints to police were more likely when the stalker was a stranger, as opposed to a former intimate partner; when the stalking involved serious physical or psychological harm to victims; and when it persisted longer than a few weeks or months (e.g., Brewster 2001; Nicastro et al. 2000). Second, the management approaches that police can use are quite different from those that can be used by victims.

\section{Police Surveys}

Very little is known about the how police manage risk for stalking and which strategies or tactics are most effective (Mullen et al. 2006). In one of the few studies conducted to date, 95 law enforcement agencies in the United States, as well as 50 in Canada, Australia, and Great Britain, were surveyed about management of risk for stalking (National Institute of Justice 1993). The findings indicated that agencies used many different approaches, even in jurisdictions that had specific anti-stalking laws. For example, police from $81 \%$ of agencies in jurisdictions with antistalking laws identified charging the stalker with nonstalking offenses (such as trespassing), an approach also used by $74 \%$ of agencies in jurisdictions without an antistalking law. Other approaches indentified by police included court-mandated mental health assessment of the stalker, electronic monitoring of the stalker, and monitoring of the stalker by uniformed officers.

\section{The Present Study}

The most general conclusion from research to date is that police and victims report using many different specific tactics to discourage stalkers. But there is no comprehensive or systematic taxonomy of risk management tactics used by police for stalking that can be employed to determine what was done in a particular case of stalking and evaluate its effectiveness, or to decide and communicate about what should be done in a particular case. Such a taxonomy would be of use not only with respect to the management of risk for stalking, but also the management of violence risk more generally.

As noted earlier, a taxonomy of management tactics used by victims was developed by Spitzberg (2002). Although it is both useful and detailed, we chose to develop a different taxonomy, because Spitzberg's (2002) taxonomy was focused on management by victims but we wanted to focus on management by police.

In the current paper, we developed a taxonomy of policebased approaches to the management of stalking. To help organize our work, we divided the general concept of management approaches into two categories: tactics and strategies. Tactics were defined as specific activities or procedures designed to promote desistance of stalking. In contrast, we defined strategies as more general types of approaches for promoting desistance- or, put differently, a set of activities or procedures that are designed to achieve the same objective in a similar way. For example, a general strategy such as mental health treatment for the perpetrator may comprise many specific tactics such as individual counseling or psychotherapy for the perpetrator, group counseling or psychotherapy for the perpetrator, and pharmacological therapy for the perpetrator, each of which could be further specified, depending on the preferred level of detail (e.g., treatment with anxiolytic medications for perpetrator). This usage is summarized in Table 1.

Our work in developing the taxonomy of police-based management tactics and strategies comprised three steps. The first step was an extensive literature review, conducted to identify risk management tactics suggested and used in various studies. Second, the list of tactics compiled from that review was presented to a group of police officers who helped to identify strategies by grouping the tactics into logical categories. Third, we examined a series of stalking cases to determine the principles behind how management tactics and strategies are coordinated and implemented in practice. This final step also involved examining the apparent effectiveness of the tactics, strategies, and principles used. We had two overarching research questions:

(1) What specific tactics and general strategies were used by police or in a policing context to manage risk for stalking?

(2) How effective were the management tactics and strategies that were implemented?

We framed our questions in this way, rather than as formal hypotheses, as our research was exploratory and qualitative in nature rather than confirmatory and quantitative.

\section{Method}

\section{Procedure}

The literature on stalking management was reviewed in search of articles that discussed or suggested management tactics for stalking. A total of 25 articles were found and the management tactics in those articles were complied into a comprehensive list (Collins and Wilkas 2001; Danto 2001; Dressings et al. 2005, 2006; Fremouw et al. 1997; Geberth 1992; Hoffmann and Sheridan 2005; Logan et al. 2006a, b; Maxey 2001; McCann 2006; McCann 2001; Mechanic 
Table 1 Defining risk management terms

\begin{tabular}{lll}
\hline Term & Definition & Examples \\
\hline Tactic & $\begin{array}{l}\text { A specific activity whose ultimate goal is to promote } \\
\text { desistance of stalking or decrease the vulnerability } \\
\text { of victims }\end{array}$ & $\begin{array}{l}\text { a) Victim installs security bars on windows at residence } \\
\text { b) Victim got an unlisted telephone number } \\
\text { c) Police ask stalker to read and sign a warning letter indicating } \\
\text { that he has been directed not to have further contact with victim } \\
\text { a) Increases physical security at residence }\end{array}$ \\
$\begin{array}{lll}\text { A group of tactics that have the same proximal goal } \\
\text { or achieve the ultimate goal in a similar way }\end{array}$ & $\begin{array}{l}\text { b) Increases telephone security } \\
\text { c) Police warn stalker not to have further contact with victim }\end{array}$ \\
\hline
\end{tabular}

Note. Tactic a would be grouped into Strategy a etc.

2002; Mester et al. 2006; Mullen et al. 2000a, b; Pathé 2002; Pathé and Mullen 1997; Römkens 2006; Sheridan et al. 2003; Snow 1998; Spence-Diehl and Potocky-Tripodi 2001; Spitzberg 2002; Spitzberg and Cupach 2001; Ugolini and Kelly 2001). The typical management tactics employed by the Domestic Violence and Criminal Harassment Unit (DVACH) of the Vancouver Police Department (VPD), where the case review was completed, were also included in the list of tactics.

The list of tactics was grouped into categories such as tactics used in the home, at work, and those employed by the criminal justice system, etc (for examples see Table 1). The list was then presented to a group of 17 police officers attending a risk assessment training course. Officers were asked to review the list for completeness and to determine if tactics were correctly grouped. Based on their comments the list of tactics was divided into 22 general strategies.

The 22 strategies were then used to code the DVACH case files. (A copy of the form is available from the authors.) As the case files were police files, coding ended when the police action and case files did. The only exception was one case which appeared to be closed, however, it was later determined that the perpetrator had continued with his stalking behavior after coding was completed. The recidivism was noted but the coding of the case was not altered.

\section{Stalking Relationship}

The relationship between the stalker and the victim was coded using the RECON (RElationship and CONtext) typology developed by Mohandie et al. (2006). The RECON typology identifies four classes of relationships: (a) intimate stalkers, who offend against individuals with whom they shared an intimate relationship, (b) acquaintance stalkers, who had employment-related, friendship, or client-based relationships with their victims, (c) public figure stalkers, who pursue public figures with whom they have had little or no direct contact and, (d) private stranger stalkers, who pursue strangers with whom they have had minor contact. The reason for using a typology is that some researchers have hypothesized that certain management strategies and tactics are likely to be more effective with certain types of stalkers (McCann 2001).

\section{Risk for Stalking}

To measure the presence of individual risk factors for stalking in a given case, as well as the overall risks posed by a perpetrator, we used the Guidelines for Stalking Assessment and Management (SAM; Kropp et al. 2008a). The SAM is a set of structured professional judgment guidelines for the assessment and management of stalking risk. It was created based on a systematic review of the scientific and professional literature related to stalking. The SAM comprises a total of 30 risk factors, 10 risk factors from each of three domains: Nature of Stalking, Perpetrator Risk Factors, and Victim Vulnerability Factors (see Table 2). Using the SAM, evaluators code the presence of each risk factor (as Present, Possibly or partially present, and Absent) during the most recent and any past patterns of stalking behavior; rate the relevance of these risk factors with respect to judgments of the risks for future stalking posed by perpetrators and the management of those risks; develop detailed risk management plans; and then make ratings that included (inter alia) case prioritization, global judgments of the overall risk for stalking posed by a perpetrators coded on a 3-point ordinal scale (Low/Routine Priority, Moderate/Elevated Priority, High/Urgent Priority).

As the SAM is a new measure, there are only a few published evaluations of the instrument. Storey et al. (2009) reported moderate interrater reliability between two trained raters who coded the files of 62 convicted stalkers: $\mathrm{ICC}_{1}$ (single rater, random effects model, absolute agreement method) for presence ratings across the three domains of risk factors was .77 for Nature of Stalking, .68 for Perpetrator Risk Factors, and .63 for Victim Vulnerability Factors. The SAM has also been evaluated in law enforcement and forensic mental health settings (Belfrage and Strand 2009; Kropp et al. 2008a, b). The present study 
Table 2 Guidelines for stalking assessment and management: domains and factors

\begin{tabular}{lll}
\hline Nature of Stalking Factors & Perpetrator Risk Factors & Victim Vulnerability Factors \\
\hline N1. Communicates about victim & P1. Angry & V1. Inconsistent behavior toward perpetrator \\
N2. Communicates with victim & P2. Obsessed & V2. Inconsistent attitude toward perpetrator \\
N3. Approaches victim & P3. Irrational & V3. Inadequate access to resources \\
N4. Direct contact with victim & P4. Unrepentant & V4. Unsafe living situation \\
N5. Intimidates victim & P5. Antisocial lifestyle & V5. Problems caring for dependents \\
N6. Threatens victim & P6. Intimate relationship problems & V6. Intimate relationship problems \\
N7. Violent toward victim & P7. Non-intimate relationship problems & V7. Non-intimate relationship problems \\
N8. Stalking is persistent & P8. Distressed & V8. Distressed \\
N9. Stalking is escalating & P9. Substance use problems & V9. Substance use problems \\
N10. Stalking involves supervision violations & P10. Employment and financial problems & V10. Employment and financial problems \\
\hline
\end{tabular}

was not designed to evaluate the utility of the SAM in predicting and preventing stalking as coding did not include suggesting or implementing management strategies for the cases reviewed and a follow up review of recidivism was not completed. As the SAM was developed only recently, it was only used by the DVACH detectives in four of the cases reviewed, and so its utility when used in practice could not be assessed.

The first author (JES) coded the SAM for all cases. At the time, JES was a masters-level graduate student in forensic psychology trained in the use of the SAM and experienced with the files and procedures of DVACH. Interrater reliability was evaluated in a subsample of 14 cases by two raters, who were blind to the first set of ratings. A subsample was coded due to the practical limitations of bringing individuals into the police department. The raters were doctoral-level graduate students in forensic psychology, who were also familiar with the files and procedures of DVACH and trained on the SAM. Interrater reliability was indexed using $\mathrm{ICC}_{1}$, calculated using a single rater two-way mixed effects (absolute agreement) model. The presence ratings of risk factors in the three domains were good to excellent and the case prioritization ratings, indexed using weighted kappa, were fair (see Table 3). Interrater reliability was moderate to high for the total number of tactics and strategies used (see Table 3). Overall, 15 cases (47\%) were judged to be Low/

Table 3 Interater reliability

\begin{tabular}{ll}
\hline Measure & $\mathrm{ICC}_{1}$ \\
\hline Nature of Stalking & .91 \\
Perpetrator Risk Factors & .92 \\
Victim Vulnerability Factors & .72 \\
Case prioritization ratings & .44 \\
Total number of tactics used & .76 \\
Total number of strategies used & .74 \\
Total number of themes & .79 \\
\hline
\end{tabular}

Routine Priority, 12 (37\%) to be Moderate/Elevated Priority, and $5(16 \%)$ to be High/Urgent Priority.

Evaluating the Efficacy of Strategies and Tactics

A qualitative research procedure known as Grounded Theory (GT) was used to examine which tactics and strategies were most and least effective at reducing or ending the perpetrator's stalking behavior. GT is a type of qualitative analysis that permits the researcher to develop theories, hypotheses, and concepts from the data rather than from prior assumptions (Taylor and Bogdan 1998). GT also allows the researcher to pursue uncharted areas of dynamic phenomena (Charmaz 2008a). A common use of GT is to account for processes in the empirical world and relationships within those processes (Charmaz 2008b), and the primary objective of GT is to produce theories from the data that account for the data (Charmaz 2008a). This objective is accomplished by examining cases as a whole as opposed to individual variables. A major benefit of GT is that it takes into account the unforeseen, thereby allowing the researcher to pursue discoveries they could not have anticipated prior to conducting their research. These qualities make GT ideal for exploratory analyses (Charmaz 2008b).

Based on these qualities GT was selected for the current analyses due to the exploratory nature of the research questions and the limited research literature. All of the qualitative analyses used common GT techniques to help organize and identify patterns in the data and then group the data into themes. The first technique employed was memo writing. Memos are used to capture the researcher's ideas while they are in the process of analyzing and can be written at any time from data collection to writing a manuscript (Glaser 1998). Memos were written at several stages during data collection and analysis including; i) after each case was coded (to highlight key concepts or note processes that may be emerging), ii) while analyzing the 
data (to summarize key points in each case) and, iii) after themes were discovered in the data (to properly define the themes and establish boundaries for inclusion). Glaser (1998) cautions that you must define each theme according to the elements found in all cases; memo writing helped to scrutinize the themes and ensure that they were supported by the data.

Theoretical sampling was used to test themes and categories and establish boundaries. Theoretical sampling involves examining cases that are similar in several aspects (e.g. process, tactics used, etc.) but have different outcomes. This comparison allows the researcher to uncover key causal differences that assist in refining the definition of a theme (Charmaz 2008a).

Tables and flow charts were also used to examine and compared the cases as they progressed over time and encountered similar milestones. For example, a table including the tactics from each case that had negative effects was created so that the tactics and the perpetrator's response to those tactics could be compared.

Using GT, themes were uncovered which related to the final tactics or strategies employed in the cases. Final management tactics were defined as those that preceded the perpetrator's desistance and, once implemented, were not followed by any further stalking behavior. Cases are closed when no further action is required by police, which in the case of stalking means that the stalking behaviour had ceased. All of the files coded in this study were closed cases. The definition of the final tactic used herein does rely on the victim to report further stalking behaviour. Given that the victims had previously reported stalking behaviour to police on at least one occasion it was assumed that they would do so again if the behaviour continued. Furthermore, once stalking cases were taken on a single DVACH detective was assigned to the case and would interact personally with the victim, who was also given the detective's contact information. Thus victims could report incidents to a single individual whom they had met instead of calling 911. DVACH detectives also often phoned victims to see if further contact had been made. Despite these safeguards, if the perpetrator continued to stalk the victim, without the victim's knowledge, it would have gone undetected for the purposes of this study.

Ineffective tactics or strategies were defined as those that repeatedly failed to facilitate the stalker's desistance as well as those that had a negative effect on the case. A negative effect was defined as an increase in stalking behavior, or a statement by the perpetrator that demonstrated the ineffectiveness of the strategy or tactic.

After the themes were identified and defined, their presence or absence was evaluated in each case. Interrater reliability for the total number of themes present in each case was excellent (see Table 3).

\section{Cases}

Cases were selected from the files of the DVACH unit of the VPD. Vancouver is a medium - to large-sized city in the Western Canadian province of British Columbia. According to the most recent census data, the city has about 600,000 residents and is the center of metropolitan area of about 2.1 million people. According to the VPD website, as of 1 January 2010 the VPD had about 1,327 sworn members and 389 civilian employees.

Detectives from DVACH investigate complaints of criminal harassment made directly to the unit or referred by patrol officers. The unit is a specialized stalking unit whose detectives participate in risk assessment training offered by expert psychologists in the field, have close ties to a number of psychologists who work in the area of stalking, and have access to the SAM, which, at the time of data collection, has not yet been widely disseminated

After the project was approved by the agencies involved, 32 DVACH case files were identified that met the following criteria: (a) the case fit the definition of stalking (discussed previously), according to the results of investigation and follow up; (b) at least some aspect of the complaint was found to be valid (i.e., credible and actionable); and, (c) the case was recently closed (i.e., the initial complaint was not still under active investigation as the stalking behaviour had ended). Case files typically contained incident reports (of the current and previous offences), criminal records, statements from the victim and others who may have witnessed stalking behaviour and officer notes from interviews with the perpetrator and victim.

The demographics of perpetrators and victims in the 32 cases resembled those reported in the stalking literature (e.g., Meloy 1999; Tjaden, and Thoennes 1998). Most perpetrators were male $(n=29,91 \%)$. The median age was 42 years. Most $(n=27,84 \%)$ were single. A substantial minority was unemployed $(n=13,41 \%)$ and had a history of treatment for mental health problems $(n=10,31 \%)$. Nine $(28 \%)$ perpetrators were not Canadian citizens. Six perpetrators (19\%) had previously been convicted of offenses, five of them for violent crimes. Four perpetrators $(13 \%)$ had previously been investigated for complaints of stalking against a different victim. Most of the victims were female $(n=27,84 \%)$, with an average age of 36 years. Two $(6 \%)$ of the victims, both public figures, had previously been stalked by different perpetrators.

Based on the RECON typology 14 the perpetrators were intimate stalkers, and in half of those cases $(n=7)$ there was a history of intimate partner violence by the perpetrator prior to the dissolution of the relationship. Of the remaining perpetrators $10(31 \%)$ were acquaintance stalkers, 7 (22\%) were public figure stalkers and $1(3 \%)$ was a private stranger stalkers. 
The average duration of the stalking at the time the case file was opened by DVACH was 523 days $(S D=735)$, with a range from 23 days to 3726 days (i.e., more than 10 years). Victims waited an average of 357 days $(S D=$ 698 ) before making a complaint to police. By definition, all of the cases involved the perpetrator having unwanted contact or communication with the victim; but almost half $(47 \%)$ of the cases also involved explicit threats of physical harm toward the victim, and three cases $(9 \%)$ involved physical violence toward the victim (i.e., assault or sexual assault). After case files were opened by DVACH, it took an average of 165 days ( $S D=223$, range 1 to 1131 days) before perpetrators desisted stalking and files were closed.

Two case vignettes are provided in Appendices A and B as general examples of the cases encountered and how they progressed. The vignettes also include examples of some of the themes uncovered in this study. Identifying information was removed from the vignettes.

\section{Results}

What Specific Tactics and General Strategies Were Used?

Prior to contacting police, the median number of tactics employed by victims in an attempt to end the stalking behavior was 4 (range 0 to 10). The number of tactics employed and the relationship between the victim and the perpetrator did not vary as a function of the length of time that victims waited to call police after the stalking began.

Following police intervention, the median number of tactics employed in each case by police, victims, and others (e.g., employers, friends, family) was 19 (range 1 to 52). The total number of tactics employed was unrelated to the nature of the relationship between the victim and the perpetrator, according to the RECON typology. The median number of tactics employed in low, moderate, and high risk cases was 15,20 , and 21 , respectively (the values were not significantly different).

A median of 7 strategies (range 1 to 14) were used in each case. Table 4 demonstrates the number of cases in which each management strategy was employed as well as the total number of times that each strategy was employed throughout all 32 cases. Legal strategies were used most often, which makes intuitive sense but is also likely due to the nature of the sample. The legal strategy category was broad and included tactics that dealt directly with the legal system or were performed by those within the legal system (e.g., warning letters, arrests).

Eighteen $(56 \%)$ perpetrators were arrested, $16(50 \%)$ were formally charged, six $(19 \%)$ were convicted of an offence, and two $(6 \%)$ were still awaiting trial. The low conviction rate is notable given that the DVACH unit handles the most serious stalking cases in Vancouver. This suggests that police resolve many cases using alternative methods such as formal warnings, and peace bonds (a criminal restraining order which does not appear on the perpetrator's criminal record). The most common legal tactic, aside from calling police $(n=27)$, was a formal police warning which was used in 19 cases $(59 \%)$ and was one of the final tactics employed in nine cases (29\%). Formal warnings consisted of a warning letter and a discussion with police which often consisted of an official interview.

Peace bonds and a single civil restraining order were issued in six cases and were subsequently violated in two $(33 \%)$ cases. Of the 18 arrests made, 13 resulted in conditions being placed upon the offender when they were released on bail. In seven (54\%) cases the perpetrator violated those conditions, and in two cases the perpetrator did so twice. Furthermore, five perpetrators had both peace bonds and court imposed conditions. Of those five, two violated both their peace bond and their conditions, one violated neither, and two complied with the peace bond but violated their court imposed conditions. No qualitative differences in risk level or RECON typology were apparent between those who violated peace bonds and those who violated court orders.

Charges were laid in 16 cases. In one case, a charge was the final tactic and in 5 cases charges led to the final tactic (i.e., a conviction). Perpetrators were most often charged with criminal harassment $(n=10)$; six were charged with multiple offenses.

In spite of the large number of management tactics employed there were several tactics uncovered in the literature review that were not used in any of the cases. For example, none of the victims filed civil charges, hired a lawyer, or contacted Cyber Angels (an online resource that offers information on internet safety issues). Conversely, several management tactics employed were not suggested in the literature. For example, in one case, the police gave the victim an information package to carry with her to other countries. The package was to be given to authorities if the perpetrator continued to engage in stalking and was meant to facilitate case management. The package contained the offender's picture, the lead detective's contact information, and instructions for authorities on how best to manage the perpetrator.

How Effective Were the Management Tactics and Strategies?

Using GT individuals who implemented tactics just prior to the stalker's desistance and the tactics or strategies that they implemented immediately preceded desistance were examined and a total of eight themes were uncovered. In the majority of 
Table 4 Stalking management strategies and tactics used

\begin{tabular}{|c|c|c|c|}
\hline Strategy & Example tactic & $\begin{array}{l}\text { Cases in which a tactic } \\
\text { from the category was } \\
\text { employed }\end{array}$ & $\begin{array}{l}\text { Total number of times that a } \\
\text { tactic from the category was } \\
\text { employed }\end{array}$ \\
\hline Legal tactics & Arrest & 31 & 209 \\
\hline $\begin{array}{l}\text { Managing contact } \\
\text { from the offender }\end{array}$ & $\begin{array}{l}\text { The victim avoided and/or never initiated } \\
\text { contact with their stalker }\end{array}$ & 27 & 75 \\
\hline $\begin{array}{l}\text { Reaching out for the } \\
\text { assistance of others }\end{array}$ & $\begin{array}{l}\text { The victim told a friend or relative about } \\
\text { being stalked }\end{array}$ & 19 & 43 \\
\hline $\begin{array}{l}\text { Obtaining professional } \\
\text { assistance }\end{array}$ & $\begin{array}{l}\text { The victim sought the assistance of a counsellor, } \\
\text { psychologist or psychiatrist }\end{array}$ & 15 & 26 \\
\hline $\begin{array}{l}\text { Taking an offensive } \\
\text { approach }\end{array}$ & $\begin{array}{l}\text { The victim documented and collected evidence } \\
\text { against the stalker }\end{array}$ & 14 & 36 \\
\hline Personal security & $\begin{array}{l}\text { The police helped the victim to create } \\
\text { a safety plan }\end{array}$ & 14 & 29 \\
\hline Telephone security & The victim changed their phone number & 13 & 38 \\
\hline Internet security & $\begin{array}{l}\text { The victim sought assistance from Cyber } \\
\text { Angels or another form of online } \\
\text { victim assistance }\end{array}$ & 12 & 24 \\
\hline Lifestyle changes & The victim moved residence & 11 & 20 \\
\hline Contacting the offender & $\begin{array}{l}\text { Told victim had a third party communicate } \\
\text { to the perpetrator that contact was unwanted }\end{array}$ & 9 & 14 \\
\hline $\begin{array}{l}\text { Protecting personal } \\
\text { information }\end{array}$ & $\begin{array}{l}\text { The victim removed their contact details } \\
\text { from public records }\end{array}$ & 9 & 13 \\
\hline Work security & $\begin{array}{l}\text { The victim developed a safety plan } \\
\text { with workplace security }\end{array}$ & 8 & 13 \\
\hline $\begin{array}{l}\text { Contacting those close to } \\
\text { the offender }\end{array}$ & $\begin{array}{l}\text { Contact was made with the parents } \\
\text { of the perpetrator }\end{array}$ & 8 & 10 \\
\hline Miscellaneous tactics & $\begin{array}{l}\text { The victim requested financial assistance } \\
\text { from the government or other agency }\end{array}$ & 7 & 9 \\
\hline Home security & Security system & 6 & 17 \\
\hline Walking security & $\begin{array}{l}\text { The victim avoided distractions when } \\
\text { walking, e.g. headphones }\end{array}$ & 5 & 7 \\
\hline School security & $\begin{array}{l}\text { The victim provided copies of court orders } \\
\text { to school officials }\end{array}$ & 4 & 6 \\
\hline Vehicle security & $\begin{array}{l}\text { The victim switched vehicles with a friend } \\
\text { or family member }\end{array}$ & 3 & 4 \\
\hline Education & $\begin{array}{l}\text { Police helped the victim to develop/learn } \\
\text { skills to deal with approaches by stalker }\end{array}$ & 2 & 3 \\
\hline $\begin{array}{r}\text { Protecting secondary } \\
\text { victims/dependents }\end{array}$ & $\begin{array}{l}\text { The victim informed their children of } \\
\text { emergency plans }\end{array}$ & 2 & 2 \\
\hline Coping on a personal level & The victim used relaxation techniques, e.g. meditation & 1 & 1 \\
\hline Transportation security & The victim waited for transportation in well lit areas & 1 & 1 \\
\hline
\end{tabular}

cases $(n=19)$ more than one management tactic was implemented immediately prior to a stalker's desistance. As a result, some cases include more than one theme. As previously mentioned one case was dropped as the perpetrator did not desist.

The first pattern, present in 28 cases $(90 \%)$, was that at least one of the final tactics employed was a legal strategy. Legal tactics are enforced or implemented by individuals in the criminal justice system; some examples include a warning letter, monitoring, a peace bond, and conviction.

The second theme was also a legal tactic. In four (13\%) cases the lead detective deliberately developed a relationship with the perpetrator or with a family member of the perpetrator, which we termed informant development. This relationship allowed the detective to maintain open lines of communication so as to monitor the perpetrator's disposition and activities. All four cases were low risk. In three cases, the relationship was between the lead detective and the perpetrator. When interviewed, all of the perpetrators responded very positively when the detectives explained that their behavior was illegal and was negatively affecting the victim. In one case, the detective used this tactic to monitor the perpetrator's priorities through phone calls and find leverage to motivate the perpetrator to not behave criminally. In another case, the perpetrator chose to inform the detective about all of the progress he had made since the offence, including: going to therapy, abstaining from 
alcohol, returning to school, and spending time outside of his home. In the fourth case the detective maintained a relationship with the perpetrator's parents and through that relationship received updates on the perpetrator's whereabouts and mental state.

The third theme, also encompassed by legal strategies, was the use of informal tactics that closely fit the details of the case $(n=5,16 \%)$. Informal tactics are not necessarily taught to police as standard procedure but are the product of experience in managing difficult cases. For example, in one case the perpetrator had a history of stalking mental health professionals with whom he came into contact and obtaining information about them through his own medical and criminal records. This same pattern was also present in his current stalking behavior. The perpetrator's actions were placing the victim and the victim's coworkers at risk of harm. In addition he was unresponsive to several standard police tactics, so the lead detective chose to use an informal tactic. The lead detective surmised that he could facilitate desistance and prevent future stalking by preventing the perpetrator from obtaining further information from the police department about the victim or other professionals involved in his case. After employing this informal tactic the perpetrator desisted.

The fourth theme, also a legal strategy was that in five cases $(16 \%)$, the final tactic employed required police to enlist the assistance of border services and/or law enforcement agents from other jurisdictions.

The fifth theme constituted cases in which the final tactic involved mental health services which ranged from counseling to involuntary inpatient treatment $(n=7,23 \%)$. For example, in one case police suggested, and the crown agreed, to drop charges when they learned that the perpetrator was receiving inpatient mental health treatment.

The sixth theme was victim implementation, as victims implemented the final management tactics in four (13\%) cases. In two cases the victim relocated and did not disclose the location of their new residence. In the additional two cases the victim reached a settlement with the perpetrator. Both of these victims had previously been in an intimate relationship with the perpetrator and were in the process of dividing assets or determining custody.

The seventh theme involved perpetrators who had a hand in their own desistance. This occurred in three cases $(10 \%)$. For example, in one case the perpetrator relocated and found a job; interestingly part of his anger towards the victim was due to the loss of his previous job.

Finally, in three cases $(10 \%)$, family members implemented one of the final tactics. In one case it was a family member of the victim and in two cases it was the perpetrator's family. For example, in one case the parents of the perpetrator paid for perpetrator to fly home (which was in another country) and once there closely monitored his actions as well as his attendance and progress in treatment.

\section{Ineffective Strategies}

A total of six ineffective or negative themes were uncovered the first of which was the negative effect of contact between the victim and the perpetrator. Victims' having purposeful contact with the perpetrator occurred in $12(37.5 \%)$ cases and had a negative effect in eight cases (25\%). An example of such contact would be a victim who responded to an email or spoke with the perpetrator by phone. In four of the eight cases the negative outcome associated with the contact was an escalation in the stalking behavior. For example, in one case, the victim agreed to meet with the perpetrator in a public place in an attempt to resolve his grievance with her. The meeting ended with an angry confrontation in which the perpetrator sexually assaulted the victim (see Appendix A). In the other four cases the victims' contact with their stalkers prompted continued contact by the stalkers. For example, at the commencement of a case the perpetrator (Greg) was maintaining regular mutual contact with a member of the victim's family (Carly). After several weeks of stalking behavior by Greg towards the victim, Carly cut contact with Greg. Almost immediately, Greg ceased his stalking behavior. The stalking resumed several months later, when Carly resumed contact with Greg. Finally, Carly cut all contact with Greg and told him never to contact anyone in the family again. The stalking ended and has not resumed. Please note that all names have been changed to protect the identities of those involved.

The exceptions to this negative management principle were two types of victim-perpetrator contact that seemed to assist in the resolution of a subset of cases. The first type of contact, which occurred in two cases, was between divorcing couples where contact was limited to court, or to reaching a settlement. In this context, contact seemed to facilitate the desistance of stalking behavior in two cases. The second type of contact was implemented for strategic purposes and was suggested and overseen by police in two cases. For instance, when a victim was receiving anonymous death threats, police had her call the suspected perpetrator while they listened and coached her on what to say. The phone call did not result in an admission of guilt by the perpetrator, but it clarified his motivation for making the death threats.

A related theme or management principle that was also ineffective was when victims left themselves open to contact from the perpetrator. Seven $(22 \%)$ victims left themselves open to contact (e.g., by phone or email), often because they thought this would provide a venue for the perpetrator to vent their feelings. However, in all seven 
cases the actions of the victim resulted in continued contact. In fact for one victim who left herself open to contact by continuing to enter a chat room (the only venue through which the perpetrator could contact her) it meant that police were unable to arrest the perpetrator. The only exception to this theme was the victim of an anonymous stalker who left herself open to contact by phone and used her caller ID to determine who the perpetrator was, which facilitated arrest.

The third ineffective management principle was informal police warnings, which were often conducted over the phone, without a formal warning letter or interview. Informal warnings were only effective in one of the six $(19 \%)$ cases in which they were employed. Moreover, the only time that the informal warning was effective, the officer making the call enhanced the warning by likening the perpetrator's circumstances to those of another perpetrator who had recently been incarcerated for stalking the same victim. The nil effect in the other five cases was particularly evident in that several perpetrators used the warning as an excuse to contact the victim, calling them to say that they did not believe a real police officer had made the warning phone call.

The fourth ineffective management principle concerned the process by which the case was managed, namely whether a united front was presented between the police and the victim. A united front is present when the police and the victim are sending the perpetrator the same message regarding the hurtfulness and illegal nature of their behavior. Such a front avoids confusion and strengthens the message being sent to the perpetrator. In four cases $(13 \%)$, a united front was not presented and its absence had a detrimental effect on the case. In all four cases the front was broken when the victim failed to report an offense or contact by the perpetrator to the police. For instance, in one case the perpetrator made it clear to police that when the victim did not report his violation of a police warning he took it as a sign that the victim enjoyed his efforts and that the police were unfairly persecuting him.

The fifth theme involves obtaining assistance from internet-based companies. Police and victims requested the assistance of internet service providers and social networking sites in four cases. In three of those cases the companies lacked the requested information, completely ignored police requests, or failed to follow through on their promise to investigate. In the remaining case, the company eventually provided the information that police requested. However, three separate police forces had to get involved before this occurred.

The final theme, having a rational discussion with the perpetrator, is somewhat different from the aforementioned themes in that it was only ineffective in a minority of cases. When interviewing perpetrators police generally spent a substantial amount of time explaining to perpetrators both that the victim did not appreciate or was frightened by their behavior as well as why such behavior was illegal. In almost all cases this management tactic provided police with insight into the perpetrator and their behavior. For some perpetrators it was also a time when they first realized or acknowledged that their behavior was inappropriate and illegal. However, four individuals (13\%) strongly rejected the explanations provided by police. In three cases this was likely due to the fact that the perpetrators held strong delusional beliefs about the victim, the legal system, or the government. For example, in one case the perpetrator, Peter, was romantically interested in the victim, Jeff. The police explained that Jeff was not homosexual in his sexual orientation and thus had no romantic interest in Peter. Peter refused to believe the police and instead decided that the government was conspiring to ruin his life and keep him from Jeff. In the fourth case the perpetrator was communicating with an individual who was close to the victim. This communication led him to hold a fixed belief that was unchanged by discussions with police.

\section{Discussion}

\section{Extra-Legal Management Tactics Indentified}

Results showed that a wide variety of management tactics, strategies, and principles outside of those typically thought of as legal strategies (arrest, charge, restraining order, etc.) were used in the cases reviewed. In addition to being extralegal many of these interventions required police to cultivate relationships with others. One such principle was a united front between the police, the victim and others involved in the case (e.g. the victim's family). Comments made by perpetrators indicated that they interpreted the lack of a united front as evidence in support of their belief that the victim condoned their behavior. As such, police should take steps to ensure that a united front is present and that the victim is aware of its importance. It should be noted that we are not suggesting the victim take any action against the perpetrator. A united from can be presented by not seeking contact with the perpetrator, not responding to their attempts at contact (e.g. not answering the phone), and by reporting all contact or breaches to the police.

Another relationship-based tactic employed by detectives was informant development with perpetrators or their families. A relationship with the perpetrator was usually established during the first meeting between the detective and the perpetrator, demonstrating the ability of officers to determine the applicability of employing this tactic in a short period of time. While these relationships were not intended to elicit desistance they did serve two other purposes. First, they established an appropriate relationship 
within which the perpetrator had someone to talk to. Stalkers tend to lack such relationships due to their poor social skills (Mullen et al. 2000a). Second, and more importantly, this relationship provided police with a great deal of useful information regarding the perpetrator's mood, their progress, and whether further intervention was needed. It also acted as a venue to suggest appropriate community services. This type of relationship may be most useful in cases that are low risk, such as those involving socially incompetent or isolated perpetrators. Both this tactic and the united front tactic highlight the importance of building rapport when effective management requires the cooperation of multiple parties.

Another extra-legal tactic was police officers' use of the mental health care system. The DVACH detectives placed a great deal of importance on appropriate mental health care for perpetrators who demonstrated signs of mental illness. Mental health services were also included among the final tactics of several cases. Additionally, in more than one case, police were amenable to dropping charges when mental health treatment was the best option for the perpetrator. The detectives who handled the cases reviewed in this study had all received training in issues related to metal illness as part of risk assessment training offered by professionals in the area. It is unclear whether this training is the reason for their response to mental illness or if it is the result of experience, or perhaps both. Whatever the reason, an understanding of mental illness is important to possess when managing this type of criminal behavior as it is an underlying factor in many cases (Meloy 1999; Mullen et al. 1999; Sheridan et al. 2003). Keeping in mind the small sample size, the knowledge that officers possessed regarding mental illness appeared to be very helpful in the cases examined.

\section{Future Research Directions}

As in any study, the data for this study were collected and analyzed in a specific fashion and had certain limitations. For example, the small sample size and use of a single police unit reduced generalizability. In addition, reliance on police records limited the available information, particularly given the fact that on average victims waited almost a year before reporting the stalking to police. The use of qualitative methods can also inject certain types of researcher bias into the analysis of the data. An effort was made to be cognizant of and to control these biases; the effect of this limitation can also be diminished in future studies by examining these research questions quantitatively.

Another limitation of this research was the use of closed case files. Closed case files were beneficial as they permitted an examination of the tactics and strategies which might have resulted in desistance. However, a close investigation of active files while they were in progress might have uncovered why police employ certain tactics and strategies and the short term effects of those tactics and strategies on stalking behaviour. Furthermore, because case management could not be observed, some tactics may have been missed. For example, police may have failed to document conversations they had with victims about safety planning.

Despite these limitations the methods chosen strengthened this study, as the small sample size allowed in-depth analysis of each case and a thorough exploration of a relatively unstudied area. One of the major goals of this study was to provide a foundation of knowledge that would guide future research in the area.

Future research could expand on the present results by gathering large sample sizes from multiple police jurisdictions in order to provide strong statistics and clear rankings of the efficacy of different tactics and strategies. This would be of great assistance to law enforcement as it would provide the officers with firm information about which tactics and strategies are the most effective, and which are the most effective at deterring different types of stalkers, or stalkers who pose different levels of risk. This information could hasten the resolution of cases, which would in turn reduce the strain on victims and police resources. This information could also be used to provide victims with persuasive evidence that supports the efficacy of tactics and strategies that they might otherwise be reluctant to undertake or follow.

Future studies that endeavor to evaluate the efficacy of management tactics or strategies should also note that there is more than one way for a tactic or a strategy to be effective. Future studies should employ a broad definition of efficacy that includes facilitating desistance, facilitating the progress of the case, and increasing the knowledge that police possess regarding the perpetrator, thereby enhancing their ability to select effective tactics and strategies.

Researchers who study stalking case management should also be mindful of the fact that while the present study found that legal tactics were highly important in facilitating the desistance of stalkers, this strategy is very broad. Merely examining the efficacy of general legal tactics that are applied to all crimes, such as arrest, peace bond and conviction, fails to provide a complete picture of the full range of tactics that police actually employ. Legal tactics such as warnings, monitoring, informant development, and informal tactics, should also be examined as they all assisted police in resolving cases in the present study. It is also important not to limit the tactics examined to those implemented by the legal system, since a subset of cases in this sample were aided substantially or resolved using 
strategies that could only be employed by mental health services, the victim, the perpetrator, or a member of one of their families.

Implication for Policy, Police, Victims, and Practice

The use of the DVACH unit in this study had benefits and limitations with respect to the conclusion that can be drawn from our results. The conclusions are limited given the small number of cases reviewed and the fact that all of the cases came from one policing unit in one city. On the other hand, the conclusions are strengthened by the resources that the DVACH unit had available including specialized training, close relationships with external experts in the area, and familiarity with the SAM, which may not be available to other police units.

One implication for practice that emerged from the results was that, where possible, warnings should be given in a formal manner which includes face-to-face contact between police and the perpetrator. Herein such warnings were more effective than warnings given informally over the telephone. The reason for this finding is unclear, however, based on comments made by perpetrators it may be that they must be convinced of the authenticity of the warning in order to comply.

The purpose of examining victim behaviour in this study was not to assign blame. Victims are not responsible for being stalked or for the actions of stalkers. Instead the purpose was to seek out ways to best manage and end stalking behaviour. As noted previously, even some of the most conscientious victims made errors in judgment, such as failing to report a perpetrator's breach of their conditions to police. Furthermore, even with police involvement it took an average of almost six months to end the stalking behaviour. These findings indicate that managing cases of stalking is neither easy nor intuitive for anyone. Thus, there exists a need to educate victims and others about how to handle stalkers. This includes teaching them what actions to take and which to avoid so that they do not reinforce the perpetrator's behavior.

Spitzberg's (2002) results suggested that victims were at a quandary regarding how to manage their situation. Our results revealed additional problems related to actions that victims were taking, which ultimately had a negative effect on the stalking (e.g., contacting the perpetrator, leaving themselves open to contact, not presenting a united front, etc.). To reduce these problems police should inform victims of what victims can do to facilitate desistance of stalking, as well as the ways in which their behavior may be misconstrued by perpetrators. When educating victims on how to facilitate desistance, police should stress adhering to the management tactics suggested, not acting in ways that might undermine police messages to the perpetrator, and applying tactics in a consistent manner. Police should advise victims that appropriate changes in their behavior can play a large role in resolving the case. In order to teach victims how to avoid having their behavior misconstrued by the perpetrator, police may find it useful to describe the general thought process of a stalker to victims. It should be noted that while we did not see evidence of such conversations between the detectives and victims in the cases reviewed, it is possible that they occurred but were not recorded in police files.

Officers should bear in mind that while they may not feel like experts in stalking, their experience with stalkers far exceeds that of the victim, who, is also likely to be highly agitated and trying to quickly learn how to navigate new territory. Officers need also be aware that things which are intuitive to them are not for victims, as stalking is fairly distinct from other social interactions. Some points that should be highlighted for victims include: (a) any attention they give to the perpetrator may be considered positive regardless of its content; and, (b) even the failure to act (e.g., by not changing their phone number or not calling police) may be construed by the perpetrator as a positive sign. Describing specific behaviors and using hypothetical examples might help to clarify the points being made. For example, a nasty letter or phone message from the victim to the perpetrator might indicate to the perpetrator that the victim was thinking of them, or chose to take the time to respond to their behavior. Conversely, such contact could be perceived as humiliating or as a personal slight and might be met with retaliation. Although there are also cases in which contact and other negative themes discussed above will not have negative results, it should be stressed that these situations are rare. Victims should be counseled to not place themselves in unnecessary danger, victims and their families should not seek out the perpetrator or try to manage the situation themselves.

Police officers can also make use of risk assessment tools like the SAM to identify vulnerable victims in need of additional assistance. The SAM is also designed to help officers identify appropriate risk management strategies based on the risk involved in the case.

Due to the nature of stalking, there will always be a need for police to collaborate with other agencies during the management of some cases (e.g. mental health services, border agencies). In the present study, collaborations were instrumental to case resolution. Conversely, only a minority of collaborations between police and internet companies even got started and the responses of the majority of internet companies were at best unhelpful. This finding is especially concerning due to the exponential increase in the use of the internet including interactive sites such as friendship sites and online chat rooms. Although beneficial in some ways, these sites also provide a new medium for stalkers to 
harass their victims. For example, Sheridan and Grant (2007) found that $48 \%$ of self-reported stalking victims said they had been harassed via the Internet. This may be an area where police need to reach out to these agencies and their security staff and cultivate a more overarching relationship, as opposed to contacting them on an as needed or case by case basis. If Internet providers are still unwilling to assist police or the victims who use their services this may be an area that will require attention from lawmakers in the future.

Overall, this study provided evidence regarding which management tactics and strategies assisted in the resolution of stalking cases, principles of case management, and questions for future research. This information is vital to improving both research and practice as it is the first step toward determining the correct dose-response relationship for managing stalking behavior. Identifying strategies and their effectiveness will help those in the field to determine what type and amount of management is needed to reduce or eliminate unwanted behavior.

Open Access This article is distributed under the terms of the Creative Commons Attribution Noncommercial License which permits any noncommercial use, distribution, and reproduction in any medium, provided the original author(s) and source are credited.

\section{Appendix A}

\section{Vignette A}

An older male (the perpetrator) had been purchasing the services of a sex trade worker (the victim). Within this business arrangement he leant her money and was also both emotionally and physically abusive to her. The victim eventually left the sex trade industry to pursue another career. The perpetrator became upset when the victim quit and stopped returning his phone calls because he said he loved her and felt they were in a relationship. The perpetrator began to follow her and threatened to tell her family about her work in the sex trade industry. The victim made contact with the perpetrator to ask him to stop but after this contact he escalated his behaviour from communication to besetting her residence. The victim then implemented several management tactics including: changing her phone number, not answering emails, altering her driving routes, staying with friends, and getting a house alarm to try to deter the perpetrator. The victim then decided to meet with the perpetrator in a public place to settle the loan in the hopes that the stalking would end. The perpetrator became angry and when she tried to walk away he followed her to a secluded area and grabbed her in an inappropriate manner.
The victim reported the assault to police. Prosecutors reviewed the results of the police investigation but were concerned there was insufficient evidence to secure a conviction for harassment or the assault. Police then gave the perpetrator a formal warning, the victim moved residences and a priority response was placed on her new home. The issue of the loan was dealt with in small claims court. Police maintained contact with the victim for seven months after the formal warning was issued, but the perpetrator made no further attempts to contact the victim.

\section{Appendix B}

\section{Vignette B}

The victim (female) and the perpetrator (male) were in an intimate relationship which ended and was followed by derogatory text messages sent by the perpetrator to the victim. Despite the texts the two tried to be friends and began seeing the same therapist. Soon after, the perpetrator initiated unwanted contact with the victim in the form of phone calls, emails, and gifts. The victim asked the perpetrator to stop contacting her and changed her email address, but these tactics were not successful. The therapist became aware of the perpetrator's behaviour and urged the victim to let the therapist handle it. The therapist's efforts did not work. When the stalking continued, the victim sent the perpetrator a very stern email. After sending the email, the victim began to receive anonymous communications and her property was vandalized on multiple occasions. The victim contacted police, but as there was no direct evidence that the perpetrator was responsible for the anonymous communications or vandalism, police issued an informal warning to the perpetrator by phone. Next, the perpetrator apparently made an obscene phone call to the victim, which she reported to police. The police gave the perpetrator a formal warning by letter, and the perpetrator acknowledged receipt through his lawyer. The victim moved to a new city to pursue a new job, and no further stalking behaviour was reported to police.

\section{References}

Alison E, Alison L (2005) A stalking management programme: Preparing advisory material for non-psychologists. In: Alison L (ed) The forensic psychologist's casebook: Psychological profiling and criminal investigation. Willan Publishing, Devon, pp 334-367

Basile KC, Swahn MH, Chen J, Saltzman LE (2006) Stalking in the United States: Recent national prevalence estimates. Am J Prev Med 31:172-175

Baum K, Catalano S, Rand M, Rose K (2009) Stalking victimization in the United States. (NCJ 224527). Department of Justice, Office of Justice Programs, Washington, DC 
Belfrage H, Strand S (2009) Validation of the Stalking Assessment and Management checklist (SAM) in law enforcement: A prospective study of 153 cases of stalking in two Swedish police counties. Int J Police Sci Manage 11:67-76

Bjerregaard B (2000) An empirical study of stalking victimization. Violence Vict 15:389-406

Blaauw E, Winkle F, Arensman E, Sheridan L, Freeve A (2002) The toll of stalking: The relationship between features of stalking and psychopathology of victims. J Interpers Violence 17:50-63

Brewster MP (1998) An exploration of the experiences and needs of former intimate stalking victims (Doc. No. 175475). West Chester University, Department of Criminal Justice, West Chester

Brewster MP (2001) Legal help-seeking experiences of former intimate-stalking victims. Crim Justice Policy Rev 12:91-112

Brewster MP (2003) The criminal justice system's response to stalking. In: Brewster M (ed) Stalking: Psychology, risk factors, interventions, and law. Civic Research Institute, Kingston, pp 321

Canadian Center for Justice Statistics (2005) Family violence in Canada: A statistical profile. Author, Ottawa

Charmaz K (2008a) Grounded theory as an emergent method. In: Hesse-Biber SN, Leavy P (eds) Handbook of emergent methods. Guilford Press, New York, pp 155-170

Charmaz K (2008b) Grounded theory in the 21st century: Applications for advancing social justice studies. In: Denzin NK, Lincoln YC (eds) Sage handbook of qualitative research, 3rd edn. Sage Publications Ltd, Thousand Oaks, pp 507-535

Collins MJ, Wilkas MB (2001) Stalking trauma syndrome and the traumatized victim. In: Davis J (ed) Stalking crimes and victim protection: Prevention, intervention, threat assessment, and case management. CRC Press, Boca Raton, pp 317-334

Danto BL (2001) Minimizing potential threats and risks to stalking victims: Case management, security issues, and safety planning. In: Davis J (ed) Stalking crimes and victim protection: Prevention, intervention, threat assessment, and case management. CRC Press, Boca Raton, pp 283-298

Dressing H, Kuehner C, Gass P (2006) The epidemiology and characteristics of stalking. Curr Opin Psychiatry 19:395-399

Dressings H, Kuehner C, Gass P (2005) Lifetime prevalence and impact of stalking in a European population: Epidemiological data from a middle-sized German city. Br J Psychiatry 187:168172

Fisher B, Cullen F, Turner M (2000) The sexual victimization of college women (NCJ 182369). Office of Justice Programs, U.S. Department of Justice, Washington, DC

Fremouw WJ, Westrup D, Pennypacker J (1997) Stalking on campus: The prevalence and strategies for coping with stalking. J Forensic Sci 42:666-669

Geberth VJ (1992) Stalkers. Law Order Mag 40:138

Glaser BG (1998) Doing grounded theory: Issues and discussions. Sociology Press, Mill Valley

Hart B (1996) Battered women and the criminal justice system. In: Buzawa ES, Buzawa CG (eds) Do arrests and restraining orders work? Sage, Thousand Oaks, pp 98-114

Hoffmann JM, Sheridan LP (2005) The stalking of public figures: Management and intervention. J Forensic Sci 50:1459-1465

Kropp PR, Hart SD, Lyon DR (2002) Risk assessment of stalkers: Some problems and possible solutions. Crim Justice Behav 29:590-616

Kropp PR, Hart SD, Lyon DR (2008a) Guidelines for Stalking Assessment and Management (SAM). ProActive ReSolutions Inc., Vancouver

Kropp PR, Hart SD, Lyon DR (2008b) Risk assessment of public figure stalkers. In: Meloy JR, Hoffman J, Sheridan L (eds) Stalking, threatening, and attacking public figures. Oxford University Press, New York, pp 343-361
Logan TK, Walker R, Jordan CE, Leukefeld CG (2006a) Women and victimization: Contributing factors, interventions, and implications. American Psychological Association, Washington

Logan TK, Walker R, Stewart C, Allen J (2006b) Victim service and justice system representative responses about partner stalking: What do professionals recommend? Violence Vict 21:49-66

Maxey W (2001) Stalking the stalker: Law enforcement investigation and intervention. In: Davis J (ed) Stalking crimes and victim protection: Prevention, intervention, threat assessment, and case management. CRC Press, Boca Raton, pp 354-360

McCann JT (2001) Legal responses. In: McCann JT (ed) Stalking in children and adolescents: The primitive bond. American Psychological Association, Washington, DC, pp 227-250

McCann JT (2006) Bullying and stalking in children and adolescents: Assessing obsessional harassment. In: Sparta SN, Koocher GP (eds) Forensic mental health assessment of children and adolescents. Oxford University Press, New York, pp 301-310

Mechanic MB (2002) Stalking victimization: Clinical implications for assessment and intervention. In: Davis KE, Frieze IH, Maiuro RD (eds) Stalking: Perspectives on victims and perpetrators. Springer Publishing Co, New York, pp 31-61

Meloy JR (1997) The clinical risk management of stalking: "Someone is watching over me...”. J Psychother 51:174-184

Meloy JR (1998) The psychology of stalking: Clinical and forensic perspectives. Academic Press, San Diego

Meloy JR (1999) Stalking: An old behavior, a new crime. Psychiatr Clin North Am 22:85-99

Meloy, J. R., Sheridan, L. Hoffmann, J. (Eds.). (2008). Stalking, threatening, and attacking public figures. New York: Oxford University Press.

Mester R, Birger M, Margolin J (2006) Stalking. Israel Journal of Psychiatry and Related Sciences 43:102-111

Mohandie K, Meloy JR, McGowan MG, Williams J (2006) The RECON typology of stalking: Reliability and validity based upon a large sample of North American stalkers. J Forensic Sci $51: 147-155$

Mullen PE, Pathé M, Purcell R, Stuart GW (1999) Study of stalkers. Am J Psychiatry 156:1244-1249

Mullen PE, Pathé M, Purcell R (2000a) Stalkers and their victims. Cambridge University Press, Cambridge

Mullen PE, Mackenzie R, Ogloff JRP, Pathé M, McEwan T, Rosemary Purcell R (2006) Assessing and managing the risks in the stalking situation. J Am Acad Psychiatr Law 34:439-450

Mullen PE, Pathé M, Purcell R (2000b) Stalking. The Psychologist 13:454-459

National Institute of Justice (1993) Project to develop a model antistalking code for states (NCJ 144477). National Institute of Justice, Washington, DC

Nicastro A, Cousins A, Spitzberg B (2000) The tactical face of stalking. J Crim Justice 28:69-82

Pathé M (2002) Surviving stalking. Cambridge University Press, New York

Pathé M, Mullen PE (1997) The impact of stalkers on their victims. British Journal of Psychiatry 170:12-17

Pathé M, Mullen PE, Purcell R (2001) Management of victims of stalking. Adv Psychiatr Treat 7:399-406

Römkens R (2006) Protecting prosecution: Exploring the powers of the law in an intervention program for domestic violence. Violence Against Women 12:160-186

Sheridan LP, Grant T (2007) Is cyberstalking different? Psychol Crime Law 13:627-640

Snow RL (1998) Stopping a stalker: A cop's guide to making the system work for you. Plenum Trade, New York

Spence-Diehl E (2004) Intensive case management for victims of stalking: A pilot test evaluation. Brief Treat Crisis Interv 4:323341 
Spence-Diehl E, Potocky-Tripodi M (2001) Victims of stalking: A study of service needs as perceived by victim services practitioners. Journal of Interpersonal Violence 16:86-94

Spitzberg BH (2002) The tactical topography of stalking victimization and management. Trauma, Violence, \& Abuse 3:261-288

Spitzberg BH, Cupach WR (2001) Paradoxes of pursuit: Towards a relational model of stalking related phenomena. In: Davis J (ed) Stalking crimes and victim protection: Prevention, intervention, threat assessment, and case management. CRC Press, Boca Raton, pp 97-136

Sheridan LP, Blaauw E, Davies GM (2003) Stalking: Knowns and unknowns. Trauma, Violence and Abuse 4:148-162

Storey JE, Hart SD, Meloy JR, Reavis JA (2009) Psychopathy and stalking. Law Hum Behav 33:237

Taylor SJ, Bogdan R (1998) Introduction to qualitative research methods: A guidebook and resource, 3rd edn. Wiley, Hoboken
Tjaden P, Thoennes N (1998) Stalking in America: Findings from the National Violence Against Women Survey (NCJ 169592). Department of Justice, National Institute of Justice, Washington

Turner JT, Gelles MG (2003) Threat assessment: A risk management approach. Haworth Press, Binghamton

Ugolini JA, Kelly K (2001) Case management strategies regarding stalkers and their victims: A practical approach from a private industry perspective. In: Davis J (ed) Stalking crimes and victim protection: Prevention, intervention, threat assessment, and case management. CRC Press, Boca Raton, pp 301-316

Victim Services Toronto. Retrieved October 30, 2008, from http:// www.victimservicestoronto.com/dv_emergency response.htm

White SG, Cawood JS (1998) Threat management of stalking cases. In: Meloy JR (ed) The psychology of stalking: Clinical and forensic perspectives. Academic Press, San Diego, pp $295-315$ 